
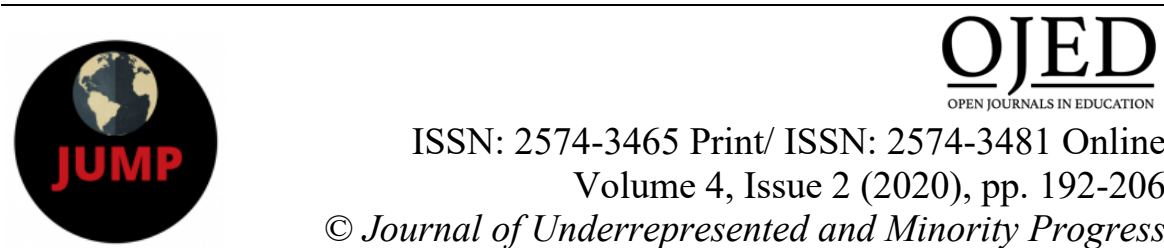

ISSN: 2574-3465 Print/ ISSN: 2574-3481 Online

Volume 4, Issue 2 (2020), pp. 192-206

(C) Journal of Underrepresented and Minority Progress

http://ojed.org/jump

\title{
Demographic and Metacognitive Variations among Female University Students in the Arabian Gulf
}

\author{
Yasser A. Al-Hilawani \\ Yarmouk University, Irbid, Jordan
}

\begin{abstract}
This study examined the presence of significant associations among demographics (i.e., monthly income and the number of family members) and metacognition (i.e., understanding pictures representing real-life situations and objects) between two groups $(N=112)$ of female university students with and without niqab (i.e., only the eyes were visible). It also explored if there were significant differences between the two groups in metacognition. Participants responded to a computerized metacognitive instrument. Correlation results revealed that the females who wore niqab were significantly and more likely to have more family members and less income when compared with the females without niqab. ANOVA analysis showed no significant differences between the students with and without niqab on the metacognitive test, in reaction time (i.e.,duration in seconds), and on the metacognitive test scores divided by the mean of the reaction times. Implications and limitations are discussed.
\end{abstract}

Keywords: demographics, females, metacognition, niqab, university students 


\section{INTRODUCTION}

Many research studies (Al-Hilawani, 2006, 2016, 2018a) used the concept of metacognition (Flavell, 1978) or the ability to think about how one thinks to examine individual differences in daily-life interactions among various groups of individuals. Traditionally, the research formats of examining metacognition are self-report, observation, think-aloud, interviews, performance rating, and diaries (Al-Hilawani, 2000, 2018b). AlHilawani, Easterbrooks, and Marchant (2002) extended the use of this concept by focusing on the understanding of one's ability to develop and understand the mental states and interpretations of events and, by extension, the mental states and intentions of others that are based on those mental states (Bartsch \& Estes, 1996) which is also called the Theory of Mind. AlHilawani et al. (2002) stated that in metacognition, the mind is the connection between the outside world and the individuals' reactions to it. They added that mental states like perceptions, intentions, emotions, desires, remembering, and thoughts are all initiated in the mind. The task of metacognition is to deduce and infer the thoughts of others and predict their behaviors where consciousness, social interactions, and experiences play a major role. Al-Hilawani et al. conceptualized metacognition in this context as simultaneous mental processing which refers to processing concurrently through the sense of vision all the elements or features of the viewed images compared to sequential and step-by-step processing as the case with linguistic processing. Individuals perform simultaneous mental processing via visual-spatial perception to explain and account for significant differences in visual analyses and discrimination of daily-life interactions (Al-Hilawani, 2003, 2006, 2008). Al-Hilawani (2003) indicated that this kind of analysis and discrimination is important for exploring individual differences in making predictions, acquiring knowledge, conducting effective interpersonal communication, and behaving and responding intelligently to events in one's environment.

Accurate analyses and interpretations are not enough for individuals to function effectively in their surrounding environment. Effective functioning depends also on their reaction time to events that could affect social interactions because individuals who are slow in responding to demands, requests, and/ or social cues may face negative consequences (AlHilawani, 2016). Initially, reaction time was studied with reference to students' intelligence quotient (IQ). Research shows that there is a correlation between reaction time and IQ; individuals with a high ability processed information faster than those with a low ability (Bates \& Stough, 1998). Reaction time was also examined in college students' emotional states. Studying undergraduate college students revealed that subjecting these students to social exclusion led to emotional distress and slow reaction 
time to the presented stimuli. Twenge, Catanese, and Baumeister (2003) reported that undergraduate students who were rejected by their peers exhibited a slower reaction time when compared with socially accepted students, who were more accurate in their estimation of the elapsed time, in a reaction time game. Social rejection affected executive functioning by slowing down responses to unfamiliar tasks but not automatic responses to familiar ones.

One approach to measuring metacognition as a simultaneous mental process is visual analyses of real-life pictures (Al-Hilawani, 2006). When implementing this approach, the individual chooses a response from the presented options to indicate which choice is the best explanation of what is being depicted (Al-Hilawani et al., 2002). This direction to metacognition makes it connected with the concept of intelligence (Al-Hilawani \& Abdullah, 2010; Al-Hilawani, 2018a) and with the visual perception which transforms visual inputs into an accurate understanding and representation of the surrounding environment (Eysenck \& Keane, 2003). Consequently, it becomes partially feasible in this context to explore the use of metacognition to account for group differences by examining exposure to different instituted cultural models that vary from one society to another and influence, at the same time, the individuals' learning and consciousness (Hollan, 2000). Al-Hilawani (2014) reported that cultural differences in interpreting daily life events and situation (i.e., metacognition in real-life situations) could be attributed to variables including knowledge of events and behaviors, familiarity with the nuances that accompany these events and behaviors, and the time needed to process and reflect on the distinctive features of events, behaviors, and actions. Al-Hilawani added that taking time to reflect and process information is a trait introduced to individuals by others like teachers and family members during social interactions in which individuals are urged to think before they act. Overall, variations in understanding and interpreting behaviors and nuances are reduced but not completely vanished when cognitively capable individuals live in the same community (Hollan, 2000). Living in the same community allows social mediation and interaction to affect the mind, shape action, and influence the interpretations of actions and events (Gauvain, 1998) in a way that interindividual differences are reduced but not necessarily eliminated because perception and exposure to instituted cultural models are not the same for any two persons even when living and/or being raised in the same community. Dweck, Chiu, and Hong (1995) revealed, in their presentation of a model which explained individual differences, that people's implicit theories and beliefs about human attributes, not to mention cognitive abilities, play a role in the way people interpret, analyze, understand, and react to the actions and outcomes of events and behaviors. Therefore, exploring the association among variables related to any phenomenon (e.g., 
metacognitive and demographic variables) might vary when studying groups of individuals with defining traits who are living in the same community.

Consistent with the notion those individual differences in beliefs and interpretations can be present in all aspects of life within and between societies, the author conducted this brief exploratory study to examine differences in metacognition, as related to the perception that leads to varying behaviors in daily-life interaction, and demographics between female participants who are wearing and not wearing a niqab (i.e., a face veil where only the eyes are visible and it is worn with an abaya, a long black gown). The author also conducted this study to find if there were significant associations, based on whether or not the participants were wearing the niqab, among the following study variables: Metacognitive test score (which refers to the correct interpretations of the visually presented stimuli), the time the participants took to respond to the presented stimuli known as reaction time, the correct responses calculated based on the mean reaction time known as the metacognitive test score based on the item mean reaction time to each test items, monthly income, and the number of family members.

Searching the literature revealed that the type of attire and headdress affects perceptions and behaviors when examined within the context of the mind and internal interpretations to appreciate and enlighten how humans transform stimuli received and perceived through the visual system into overt behaviors (Eysenck \& Keane, 2003; Margolis, 1987). Kret and deGelder (2012) reported that fear was recognized fastest by a white European sample when facial expressions were partly hidden by a niqab (i.e., only the eyes were visible) and that cap and scarf headdresses were associated with happiness. Other studies examined the metacognitive beliefs about beauty, body appearance, and attractiveness between female participants who were wearing hijab (i.e., the whole face was visible), niqab, and those who were not. For example, Swami, Miah, Noorani, and Taylor (2014) found that body image among women wearing the hijab was more positive than that of women not wearing the hijab. They did not value appearance as much as women not wearing the hijab, and they had low acceptance of media massages about beauty standards. Đurović, Tiosavljević, and Šabanović (2016) reported that females who wore the hijab were considerably less pressured to attain the western standards of beauty and had the highest level of body satisfaction even though they had the highest body weight compared to Muslim adolescent girls who did not wear hijab and followed Westerninfluenced fashion trends. Finally, Kertechian and Swami (2016) mentioned that women who wore hijab reported considerably lesser weight discrepancy, body dissatisfaction, drive for thinness, and social appearance anxiety and pressure to thin ideals than those who did not.

It is hypothesized in this brief research, based on the apparent differences between females who wore the niqab and those who did not, that 
females who wore the niqab had more family members but less income compared with the females without niqab. The author stated this hypothesis even though both groups were born in the same geographical area and regarded proper citizens of the same country. It is also hypothesized that no significant differences would exist - contrary to the literature reviewed above which focused on matters including attractiveness and body appearance (being measured subjectively from the participants' point of view as opposed to being measured objectively) - between the two groups (i.e., with and without niqab) in metacognition (i.e., interpreting via visual perception varying real-life situations) because it is associated with intelligence (AlHilawani, 2018a; Wagner, 2000). However, compared with intelligence, metacognition is considered, in this research, a process that relies on the individual's visual analyses and discriminations and regarded a private psychological process that is more likely to be enhanced and advanced through incidental learning if or when no direct coaching is involved. Metacognition, in this case, is amenable to instruction and influenced by experiences. At the same time, it converges with other traits linked to abilities needed for developing expertise to perform accurate prediction, monitor one's self, reach appropriate solutions, automatize steps and procedures to deal with the encountered issues, and possess and acquire vast knowledge in a given domain (Sternberg, 1998).

\section{Participants}

\section{RESEARCH METHOD}

The participants in this study were 114 native female undergraduates who were born and raised in the same country and held its nationality (mean age $=20.38$ years; $\mathrm{SD}=1.70$ years; age range $=17.44$ to 25.84 years; $\mathrm{n}=112$; the author deleted two cases due to missing information). They were students at a local university in the Arabian Gulf region in the Middle East. The participants had normal $(\mathrm{n}=95)$ or corrected-to-normal vision $(\mathrm{n}=19)$ when asked about their visual acuity and were not on any kind of medication before taking the test. They represented the colleges of Education $(n=77)$, Law $(n=2)$, Arts $(n=8)$, Science $(n=13)$, Engineering $(n=2)$, Allied Health Science $(\mathrm{n}=7)$, and Social Science $(\mathrm{n}=3)$. There were 29 students with niqab (mean age $=20.23$ years; $\mathrm{SD}=1.70$ years; age range $=17.57$ to 24.28 years) and 83 students without niqab (mean age $=20.44$ years; SD $=1.73$ years; age range $=17.44$ to 25.84 years). There were 29 freshmen, 35 sophomores, 30 juniors, and 18 seniors.

\section{Instrumentation}

The author used in this study the test of metacognition in real-life situations (Al-Hilawani, Dashti, \& Abdullah, 2008). This test was in a picture form and based on the work of Wellman and Gelman (1992) who 
presented three foundational knowledge domains that individuals probably used to gain certain knowledge. These three knowledge domains constituted usually the bases for later conceptual acquisitions. They were naïve physics, naïve psychology, and naïve biology. Examples of these domains, as reported in Al-Hilawani et al's (2008) study, included internal mental states such as desire, sadness, pain, fear, anger, disgust, surprise, and happiness which represented the naïve psychology domain; cause-effect relationships and understanding the identification, classification, and transformation of physical objects represented the naïve physics domain; and identifying and understanding the processes of organic growth, reproduction, inheritance, classification, eating and sleeping, and illness and death represented the naïve biology domain.

Al-Hilawani and colleagues searched the internet and Master Clips unlimited (1990-1998) to find adequate images to represent the above three domains. The Master Clips unlimited is a collection of over 303, 000 photos and images grouped into main categories and subcategories including plants, animals, people, objects, cartoons, transportations, military, and home. This process yielded 28 test items each of which consisted of a target picture and four options of pictures. One of the four options was the correct choice because it matched with or related directly to the target picture. The 28 questions comprised 12 test items representing the biology domain, 7 test items representing the physics domain, and 9 test items representing the psychology domain.

Al-Hilawani and colleagues piloted the tool in paper form with four faculty members in the college of education. They informed the reviewers that the purpose of the instrument was to measure the students' knowledge of real-life problems and situations as well as their reasoning and problemsolving skills. They asked each reviewer to comment on the clarity as well as the relationship between each target picture and the assigned four choices and indicate whether the target picture matched with or related appropriately to the correct option. This piloting process yielded a $71 \%$ agreement. The reviewers commented on 8 out of 28 items by stating that some target pictures had more than one correct option and that some options were unclear and confusing. The authors addressed all the reviewers' comments by going back to the internet and Master Clips to search for new pictures to replace the ones in question. When finished replacing these pictures, the authors asked the same four reviewers to comment again on the newly modified instrument to determine if their comments and suggestions were implemented satisfactorily. This second round of the piloting process yielded $100 \%$ agreement that there was only one correct answer among the four options that reflected correctly the relationship with the target picture and that the other three options functioned appropriately as distractors. 
The paper version of the metacognition test was then transformed into an electronic one using an IMB compatible desktop computer preinstalled with Microsoft programs. The screen resolution was set at 800 x 600 pixels for clarity of the images displayed. The author used this computerized tool to present the test content and measure accurately the students' reaction time (which refers in this study to the duration of a test item on the computer screen for the maximum of one minute. A portion of this reaction time is called inspection time (which refers to the period that is required by a participant to process accurately the presented information) which is a factor that underlies performance on the tests of intelligence (Deary \& Stough, 1996). Reaction time and inspection time are inseparable and are intertwined in this current study).

The 28 test items presented randomly and in a counterbalanced manner to each participating student. Each test item was timed to appear on the computer screen for one minute. If the student did not select within the one-minute period one of the four options as an answer to the presented picture, the next test item would appear immediately on the computer screen. The maximum time allowed to complete this test was 30 minutes: 28 minutes for the actual test and 2 minutes for the two trial exercises. The computer program assigned one point to each test question answered correctly. Thus, the maximum possible score that any student could receive was 28 out of 28 .

The author found when examining the reliability of this instrument that three items did not correlate significantly with the total score; but they were not excluded from the analyses. The correlation of these items with the total score was $.10, .13$, and .17 . The rest of the items correlated significantly with the total score; their correlation ranged from .19 to .53 . The 28 items yielded a reliability coefficient (alpha) of .73. Previous research with university students from the Arabian Gulf region showed that this instrument had a reliability coefficient (alpha) of .74 when used with male and female university students (Al-Hilawani, 2016) and .83 alpha when administered to elementary school students (Al-Hilawani, 2014).

Because responding appropriately to items on the constructed instrument depended on the individual's ability to perform visual analyses of the presented pictures in terms of similarities and differences in themes and contents, the author expected those older and more able participants with much experience to perform better than the individuals who were not as revealed in previous studies. These studies showed that the performance on metacognitive tools was influenced by the participants' age (Al-Hilawani, 2003, 2014). Therefore, a ceiling effect was expected when dealing with more capable and older participants who would probably answer correctly every item included in the instrument (Al-Hilawani, 2016). Overall, using pictures to embody these three domains was appropriate for representing various types of information, including illustrating intentions (Bloom \& 
Markson, 1998), whether or not they were presented to young or older participants.

This study collected information not only on the participants' correct responses and how much time they took to choose an answer but also on whether the correct response to each item on the test was influenced by the mean of the reaction time to that item. Therefore, the author calculated 28 means of reaction time and used them as benchmarks to decide whether a participant should receive a zero point or one point for each of the 28 test items when the selected option was correct. If the response was correct and fell at or below the calculated mean of the reaction time, the computer assigned one point for responding to that item. If the response was wrong or was correct but exceeded the assigned mean of the reaction time designated to that item, the computer gave a zero point for that particular item. Finally, the author collected additional data on each participant which included age, number of family members, and monthly income.

\section{Procedures}

The author of this study obtained all necessary approvals from the university research ethics committee as well as from each participant to conduct this study. The author informed all students enrolled in his classes that he was looking for volunteers to participate in this brief exploratory study. The announcement stated that each student agreed to take part in this study may visit the author's office to sign a consent form, fill out needed demographic and health data, and then respond to items in the form of pictures presented on a computer screen. The author did not disclose nor did he provide details on the nature of pictures that the students would be seeing on the computer screen.

The author administered the test to all participating students following steps reported in previous research (Al-Hilawani et al., 2008; AlHilawani \& Abdullah, 2010). The data collection began by administering the two training test items followed by the actual test items. Each participant sat at a table in the line of sight of the computer screen which was set at 40 centimeters away from each participant.

The author began each testing session by administering the two training test items followed by the actual test items. One training test item involved presenting on the computer screen a target picture (i.e., an apple) and four options (i.e., two kittens, three bananas, an open book, and a robot). The author asked each participant to point to the option that was related to or matched with the target picture. The second training test item depicted a target picture of a red circle and then the options of three red triangles and a red circle. The author also asked each participant to point to the shape that was related to or matched with the target picture. When students selected the best option out of the four available pictures in each one of the two training 
test items, the author clicked on that option with the mouse to store the response. When students finished taking the two-trail exercises, they proceeded to take the actual test.

While the two training items appeared easy and straight forward, the actual test items were more difficult and required accurate analyses and interpretations to find the right answer. The following two examples represented the psychology domain: A picture was selected to show a robber holding a sack of money in his hand along with four other pictures one of which showed the consequence of such act (i.e., being behind bars). The second example showed a drawing of a scared man holding a bedcover up close to his eyes and the four options of pictures one of which showed a masked man pointing a gun.

The author entered the students' answers into the computer to control for unnecessary time variations, inconsistent data entry, and/or unintended answers that would more likely to happen had the students themselves been asked to enter their answers into the computer. When a student finished taking the test, the computer program generated automatically a new set of randomized test items for the next participant. The author read and implemented the following instruction and sequence of events with each participant: The author said: "I would like to show you a game on this computer (the author pointed to the computer). I want you to try this game and then I want you to tell me if you like it. I want you to play this game fast; but I also want you to be accurate when choosing your answers". The author started the first practice test item by saying: "What is this picture? (the author pointed to the target picture). When the student answered the question, the author then said: "I want you to find a picture (the author pointed with the index finger in a sweeping manner from left to right to the four pictures underneath the target picture) that goes with this picture (the author pointed to the target picture)". When the student pointed to one of the four pictures, the author used the mouse to enter the student's answer into the computer.

The second practice test item started immediately followed by the author saying: "What is this picture? (the author pointed to the target picture)". When the student answered the question, the author then said: "I want you to find a picture (the author pointed with the index finger in a sweeping manner from left to right to the four pictures underneath the target picture) that goes with this picture (the author pointed to the target picture)". When the participant pointed to one of the four pictures, the author used the mouse to enter the student's answer into the computer.

When the participant finished the second practice test item, the author said: "Do you understand this game?" If the answer was no, the author restarted the two practice test items on the computer and repeated all the previous steps. If the answer was yes, the author said: "Do you want to go through the two practice test items again?" If the answer was yes, the author 
restarted the practice exercises. If the answer was no, the author said: "Now I will start the game. I want you to point to one of the four pictures that goes with the picture in the middle of the computer screen. Do this game fast but be accurate in your responses. Do not ask questions when the game starts because I am not allowed to talk. Shall I start the game?" If the participant decided not to play the game, the author would thank her and then finish the meeting. If the participant wanted to play the game, the author would start the game.

Because reaction time was measured, the author did not repeat instructions nor was he pointing to options during the actual test administration.

\section{RESULTS}

The metacognitive instrument yielded three dependent variables: The students' correct responses on the metacognitive test, reaction time to the metacognitive test items, and the correct responses calculated based on the mean of reaction time to each of the 28 test items. Table 1 shows the raw scores of both groups which appeared comparable on all three variables.

\section{Table 1}

Means (M) and Standard Deviations (SD) of the Metacognitive Test Scores, Reaction Time, and Test Scores Divided by Mean Reaction Time on the Computerized Tool.

\begin{tabular}{|c|c|c|c|c|c|c|}
\hline \multirow[t]{2}{*}{ Student groups } & \multicolumn{2}{|c|}{$\begin{array}{l}\text { Scores on the } \\
\text { metacognitive } \\
\text { test }\end{array}$} & \multicolumn{2}{|c|}{$\begin{array}{l}\text { Reaction time } \\
\text { in seconds }\end{array}$} & \multicolumn{2}{|c|}{$\begin{array}{l}\text { Metacognitive } \\
\text { scores divided by } \\
\text { mean reaction } \\
\text { time }\end{array}$} \\
\hline & $\underline{\mathbf{M}}$ & $\underline{\text { SD }}$ & $\underline{\mathbf{M}}$ & $\underline{\text { SD }}$ & $\underline{\mathbf{M}}$ & $\underline{\text { SD }}$ \\
\hline All females $(\mathrm{N}=112)$ & 19.85 & 2.82 & 144.22 & 32.20 & 12.59 & 4.37 \\
\hline Females with niqab $(n=29)$ & 19.17 & 2.36 & 137.03 & 26.93 & 12.93 & 3.71 \\
\hline $\begin{array}{l}\text { Females without niqab } \\
(\mathrm{n}=83)\end{array}$ & 20.06 & 2.96 & 146.71 & 33.91 & 12.46 & 4.60 \\
\hline
\end{tabular}

Also, the table shows the effect of reaction time on performance on the metacognitive instrument. It demonstrates that setting a time limit had affected negatively the number of correct responses on the metacognitive test for both groups of students. 
A point biserial correlation was conducted to find whether or not there were significant associations between the following study variables: The students' attire (i.e., with and without niqab), metacognitive test score, reaction time, metacognitive test score obtained based on the mean reaction time, monthly income, and the number of family members. Table 2 shows a significant negative association between the variables of the students' attire and the number of family members.

\section{Table 2}

A Point Biserial Correlation Result of the Students' Attire, Metacognitive Scores (MT), Reaction Time (RT), Metacognitive Scores based on Mean Reaction Time (MSRT), Monthly Income (MI), and Number of Family Members (NFM)

\begin{tabular}{|c|c|c|c|c|c|c|}
\hline Variables & Attire & MT & RT & MSRT & MI & NFM \\
\hline $\begin{array}{l}\text { 1. Attire - Niqab or No Niqab } \\
(\mathrm{N}=112)\end{array}$ & 1.00 & & & & & \\
\hline 2. Metacognitive scores $(\mathrm{N}=112)$ & .14 & 1.00 & & & & \\
\hline 3. Reaction time $(\mathrm{N}=112)$ & .12 & .11 & 1.00 & & & \\
\hline $\begin{array}{l}\text { 4. Metacognitive scores based on } \\
\text { mean reaction time }(\mathrm{N}=112)\end{array}$ & -.04 & $.47^{* *}$ & $-.72 * *$ & 1.00 & & \\
\hline 5. Monthly income $(\mathrm{N}=98)$ & $.21^{*}$ & -.05 & -.20 & .16 & 1.00 & \\
\hline $\begin{array}{l}\text { 6. Number of family } \\
\text { members }(\mathrm{N}=112)\end{array}$ & $-.24 * *$ & .02 & -.01 & -.01 & .09 & 1.00 \\
\hline
\end{tabular}

Note: $*=p<.05, * *=p<.01$

Students who wore niqab had significantly more family members compared to students without niqab. The table also shows monthly income to be positively significant, an indication that students without niqab had more monthly income compared to students with niqab. Finally, the table shows that the metacognitive test score based on the mean reaction time to be significantly and positively associated with the metacognitive test score and significantly but negatively associated with reaction time. This result reveals that the more time the students took to respond to the test items, the lower their overall scores would be on the test regardless of their attire.

The author performed ANOVA analysis to find significant differences in age, metacognitive test scores, reaction time, and metacognitive test scores divided by the mean reaction time between the two 
groups of participants. Results showed no significant differences between the two groups based on age, $\mathrm{F}(1,110)=.326, \mathrm{p}=.569($ Partial $\eta 2=.003)$, metacognitive test, $\mathrm{F}(1,111)=2.214, \mathrm{p}=.140$ (partial $\eta 2=.001)$, reaction time, $, \mathrm{F}(1,111)=1.745, \mathrm{p}=.189$ (partial $\eta 2=.015)$, or metacognitive test scores based on the mean reaction time, $\mathrm{F}(1,111)=2.975, \mathrm{p}=.699$ (partial $\eta 2=.001)$.

\section{DISCUSSION AND CONCLUSIONS}

The author conducted this brief exploratory study to examine whether there were significant associations among demographic and metacognitive variables based on the type of students' attire (i.e., niqab and no niqab) in the Arabian Gulf. The author also intended to find if there were significant differences in metacognition as related to real-life situations between the two groups of participants. Results supported the first hypothesis that females who wore niqab had more family members compared to females without niqab. Results showed that monthly income was significantly associated with the type of students' attire. Students without niqab had more monthly income compared with the students with niqab. It appeared that the significant associations of the two demographic variables (i.e., the number of family members and monthly income) with the type of students' attire revealed a distinction between the two groups of participants. Furthermore, this study showed that the more time the students took to respond to the test items, the lower their overall scores would be on the test regardless of their attire. Overall, the results indicated that a demographic variable is more likely to be associated with another demographic variable in a way better than being associated with metacognition. Further work is needed to support and shed more light on this finding.

This study showed that the metacognitive test score based on the mean reaction time was significantly and positively associated with the metacognitive test score and significantly but negatively associated with reaction time. This result revealed the influence of imposing a mean reaction time on the students' correct responses in a way that when setting a time limit to respond to stimuli, it would affect negatively the performances of both groups on the metacognitive instrument. This trend was observed in other studies with similar groups of university students (Al-Hilawani, 2016) as well as with younger individuals (e.g., Al-Hilawani et al., 2008; Al-Hilawani \& Abdullah, 2010).

The result of this study supported the hypothesis that the two female groups were comparable in their performances in metacognition, reaction time to the presented stimuli, and metacognitive scores divided by the mean reaction time. It appears that wearing the niqab is not significantly related to students' metacognitive performances. One plausible explanation is that both groups had a comparable cognitive ability which is deduced from the 
positive relationship between IQ and metacognition. Al-Hilawani (2018a) reported a significant association between IQ and metacognition, as viewed in this study, which could be a viable explanation for the lack of a significant difference in metacognition between the two groups of students. Finally, due to the nature of this brief research, results should be replicated with a larger sample of participants selected to represent various study areas and populations. The participants involved in this study were a small number of students who willingly volunteered.

\section{IMPLICATIONS}

This study showed that metacognition is not significantly associated with the type of students' attire (i.e., niqab and no niqab). However, it revealed a significant association between the type of students' attire and two demographic variables; these variables were the number of family members and monthly income. No significant association was found between the demographic variables and metacognition in real-life situations. It appeared that the social custom of wearing niqab had more influence on the variables of monthly income and the number of members in the family compared with the variables related to metacognition. Overall, there are group variations and that the significant associations between the variables related to these variations are more likely to appear when examined within their designated domains (e.g., social compared to metacognitive) but not necessarily cross domains. In general, further work is needed to examine the cross domains influences because, as a rule, everything affects everything to a certain degree. The issue is how much effect there is. Finally, it appeared that the students who were wearing and not wearing niqab not only differed in their perception of beauty, body appearance, and attractiveness, as mentioned in the literature, but also in income and the number of their family members, as found in this study. Conducting future studies in this regard may validate and shed more light on this tentative conclusion.

\section{REFERENCES}

Al-Hilawani, Y. (2018a). Rendezvous with IQ: Metacognition in real-life situations. Educational Studies, 44(2), 119-146.

Al-Hilawani, Y. (2018b). Reflection on metacognition in real-life situations: The truth is out there. Reflective Practice: International and Multidisciplinary Perspectives, 19(1), 135-144.

Al-Hilawani, Y. (2016). Metacognition in real life situations and study skills and habits: Two types of thinking. International Journal of Progressive Education, 12(1), 73-89.

Al-Hilawani, Y. (2014). Metacognition and group differences: A comparative study. Exceptionality: A Special Education Journal, 22, 173-189.

Al-Hilawani, Y. (2008). Metacognitive performances of hearing students and of students who are deaf and hard-of-hearing on two types of measures: Visual- 
voiced and visual-visual stimuli. International Journal of Disability, Development, and Education, 55, 331-339.

Al-Hilawani, Y. (2006). Visual Analyses and Discriminations: One Approach to Measuring Students' Metacognition. American Annals of the Deaf, 151, 1624.

Al-Hilawani, Y. (2003). Measuring students' metacognition in real-Life situations. American Annals of the Deaf, 148, 233-242.

Al-Hilawani, Y. (2000). A new approach to evaluating metacognition in hearing average-achieving, hearing underachieving, and deaf/hard-of-hearing elementary school students. British Journal of Special Education, 27(1), 41-47.

Al-Hilawani, Y., \& Abdullah, A. (2010). Measuring metacognition and reaction time: Further findings on the performances of general education, lowachieving, and institutionally raised students. Journal of International Special Needs Education, 13, 1-13.

Al-Hilawani, Y., Dashti, F., \& Abdullah, A. (2008). Measuring metacognition: A prospect for objective assessment. The Volta Review, 108, 139-154.

Al-Hilawani, Y., Easterbrooks, S. R., \& Marchant, G. J., (2002). Metacognitive ability from a theory-of-mind perspective: A cross-cultural study of students with and without hearing loss. American Annals of the Deaf, 147, 38-47.

Bartsch, K., \& Estes, D. (1996). Individual differences in children's developing theory of mind and implications for metacognition. Learning and Individual Differences, 8(4), 281-304.

Bates, T., \& Stough, C. (1998). Improved reaction time method, information processing speed, and intelligence. Intelligence, 26 (1), 53-62.

Bloom, P., \& Markson, L. (1998). Intentionality and analogy in children's naming of pictorial representations. Psychological Science, 9 (3), 43-47.

Đurović, D., Tiosavljević, M. \& Šabanović, H. (2016). Readiness to accept Western standard of beauty and body satisfaction among Muslim girls with and without hijab. Scandinavian Journal of Psychology, 57(5), 413- 418.

Deary, I. J., \& Stough, C. (1996). Intelligence and inspection time: Achievements, prospects, and problems. American Psychologist, 51(6), 599-608.

Dweck, C. S., Chiu, C., \& Hong, Y. (1995). Implicit theories and their role in judgments and reactions: A world from two perspectives. Psychological Inquiry, 6, 267-285.

Eysenck, M. W., \& Keane, M. T. (2003). Cognitive psychology: A student's handbook ( $4^{\text {th }} \mathrm{ed}$.). New York: Taylor and Francis.

Flavell, J. H. (1978). Metacognitive development. In J. M. Scadura \& C. J. Brainerd (Eds.), Structural process theories of complex human behavior (pp. 213-245). Ayphen \& Rijn, The Netherlands: Sijtoff \& Noordhoff.

Gauvain, M. (1998). Culture, development, and theory of mind: Comment on Lillard (1998). Psychological Bulletin, 123, 37-42.

Hollan, D. (2000). Constructivist models of mind, contemporary psychoanalysis, and the development of culture theory. American Anthropologist, 102, 538 550.

MasterClips unlimited. (1990-1998). San Rafael, CA, USA: IMSI. 
Kertechian, S. K., \& Swami, V. (2016). The hijab as a protective factor for body image and disordered eating: a replication in French Muslim women. Mental Health, Religion \& Culture, 19(10), 1056-1068.

DOI: $10.1080 / 13674676.2017 .1312322$

Kret, M. E., \& de Gelder, B. (2012). Islamic headdress influences how emotion is recognized from the eyes. Frontiers in Psychology, 3, Article 110. https://doi.org/10.3389/fpsyg.2012.00110

Margolis, H. (1987). Patterns, thinking, and cognition: A theory of judgment $\left(3^{\text {rd }}\right.$ ed.). Chicago: University of Chicago Press.

Sternberg, R. J. (1998). Metacognition, abilities, and developing expertise: What makes an expert student? Instructional Science, 26, 127-140.

Swami, V., Miah, J., Noorani, N., \& Taylor, D. (2014). Is the hijab protective? An investigation of body image and related constructs among British Muslim women. British Journal of Psychology, 105(3), 352-363.

Twenge, J. M., Catanese, K. R., \& Baumeister, R. F. (2003). Social exclusion and the deconstructed state: Time perception, meaninglessness, lethargy, lack of emotion, and self-awareness. Journal of Personality and Social Psychology, $85,409-423$.

Wagner, R. K. (2000). Practical intelligence. In R. J. Sternberg (Ed.), Handbook of intelligence (380-395). Cambridge University Press, Cambridge: United Kingdom.

Wellman, H. M., \& Gelman, S. A. (1992). Cognitive development: Foundational theories of core domains. Annual Review of Psychology, 43, 337-375.

YASSER A. AL-HILAWANI is a scholar and professor of special education at Yarmouk University, Irbid, Jordan. His research interests include metacognitive processing, assessment in special education, and teaching strategies. Kindly send correspondence to yhilawani@netscape.net

Manuscript submitted: October 9, 2019

Manuscript revised: June 23, 2020

Accepted for publication: July 5, 2020 